\title{
Liver cell dysplasia: a premalignant condition
}

\author{
P. P. ANTHONY, C. L. VOGEL, AND L. F. BARKER
}

From The Bland-Sutton Institute of Pathology, The Middlesex Hospital Medical School, London, The Solid Tumour Centre, Uganda Cancer Institute, Kampala, Uganda, and the Division of Virology, Bureau of Biologics, Food and Drug Administration of the US Public Health Service, Rockville, Maryland, USA

SYNOPSIS Liver cell dysplasia is defined as cellular enlargement, nuclear pleomorphism, and multinucleation of liver cells occurring in groups or occupying whole cirrhotic nodules. The prevalence, natural history, and relationship to the Australia or hepatitis-associated antigen (HAA) have been studied in 552 Ugandan African patients with normal, cirrhotic, and cancerous livers. Liver cell dysplasia was found in only two of $200(1 \%)$ patients with normal livers, in three of $43(6.9 \%)$ of patients with normal livers bearing primary liver cell carcinoma, 35 of $175(20.3 \%)$ patients with cirrhosis, and 80 of $124(64.5 \%)$ of patients with cirrhosis and primary liver cell carcinoma. Cirrhotic patients without dysplasia were, on average, ten years younger than those with dysplasia and the latter were on average six years younger than those with cirrhosis and carcinoma. Liver cell dysplasia occurred more frequently in males than in females. It was found in all but one instance in macronodular or mixed forms of cirrhosis only. There was a strong relationship between dysplasia and the presence of HAA in 104 patients that suggests a possible carcinogenic mechanism for the longincubation (serum or B) hepatitis virus in liver cell carcinoma. It is concluded that the presence of liver cell dysplasia identifies a group of patients with a high risk of liver cell carcinoma and that they should be followed up by serial alpha-fetoprotein estimations.

Gross morphological abnormality of liver cells in cirrhosis has been noted from time to time (Edmondson and Steiner, 1954; Steiner and Davies, 1957; Higginson and Steiner, 1961), particularly in the macronodular (posthepatitic or postnecrotic) types (Scheuer, 1968). The terms 'liver cell atypia', 'hyperplastic nodule', and 'regeneration' have been applied to this change. Steiner and Davies (1957) commented on its relative frequency in African, as compared with American cirrhotic livers. The distinction between an atypical nodule and well differentiated liver cell carcinoma may be difficult (Higginson and Steiner, 1961). However, these foci of cellular atypia have not been thought to represent a premalignant or malignant change, the arguments against this being that the histopathological features were different from carcinomas arising in the same livers (Steiner and Davies, 1957) or that such foci could persist in cirrhotic livers for years without carcinoma supervening (Scheuer, 1968). In experimental pathology similar changes may be produced by a variety of means and their interpretation remains uncertain (Butler, 1971).

Received for publication 23 January 1973.
The considerable disagreement about the true nature of this phenomenon is reflected in the variety of names applied to it. We have chosen 'liver cell dysplasia' as the most appropriate term to describe the histological appearances and the least presumptive as to their nature.

In the course of our continuing studies of primary liver cancer in Uganda we have noted an association of liver cell dysplasia with macronodular types of cirrhosis and carcinoma of liver cell, but not of bile duct, origin (Anthony, 1972), and we have also found a highly significant association with the presence of the Australia or hepatitis-associated antigen (HAA) (Anthony, Vogel, Sadikali, Barker, and Peterson, 1972). We now report the results of an extended study of its morphology, prevalence, and natural history in normal, cirrhotic, and cancerous livers.

\section{Definition of Liver Cell Dysplasia}

Minor inflammatory and regenerative changes are a common finding in livers of African patients suffering from a variety of diseases and have been frequently 


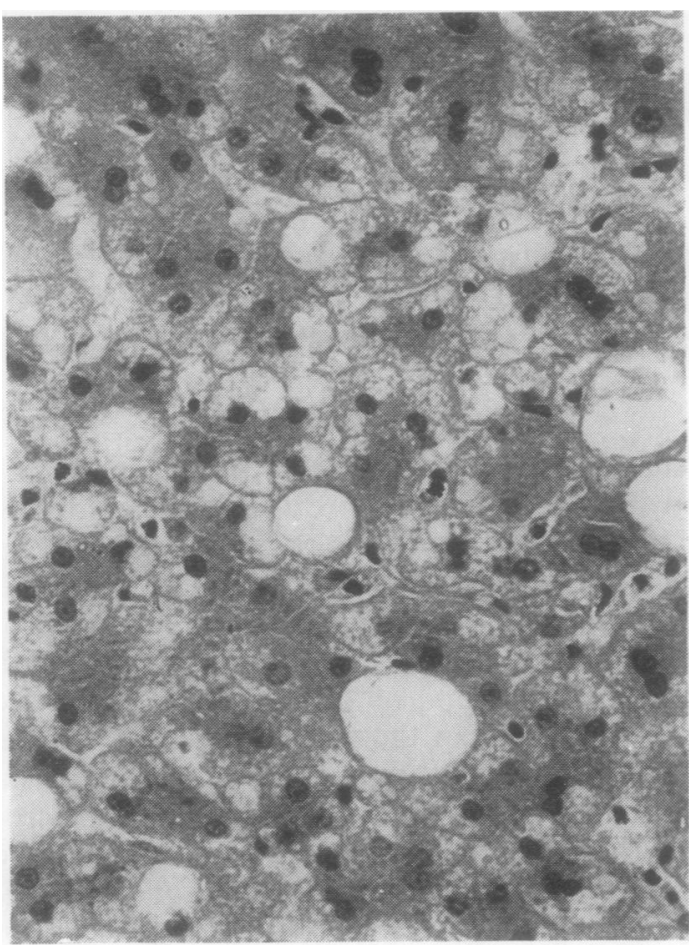

Fig. 1

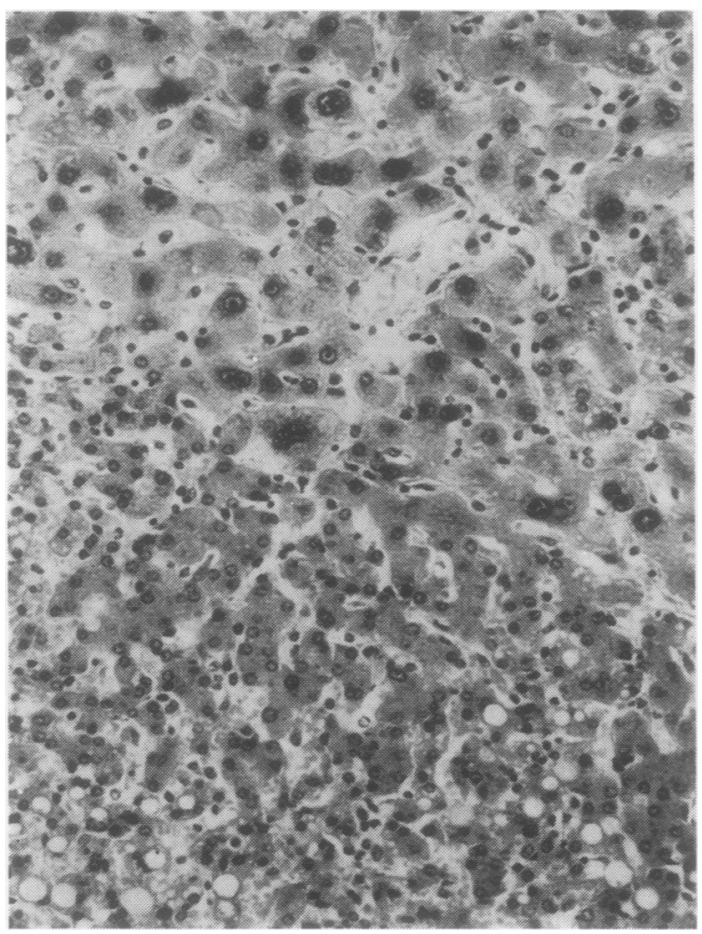

Fig. 3
P. P. Anthony, C. L. Vogel, and L. F. Barkero

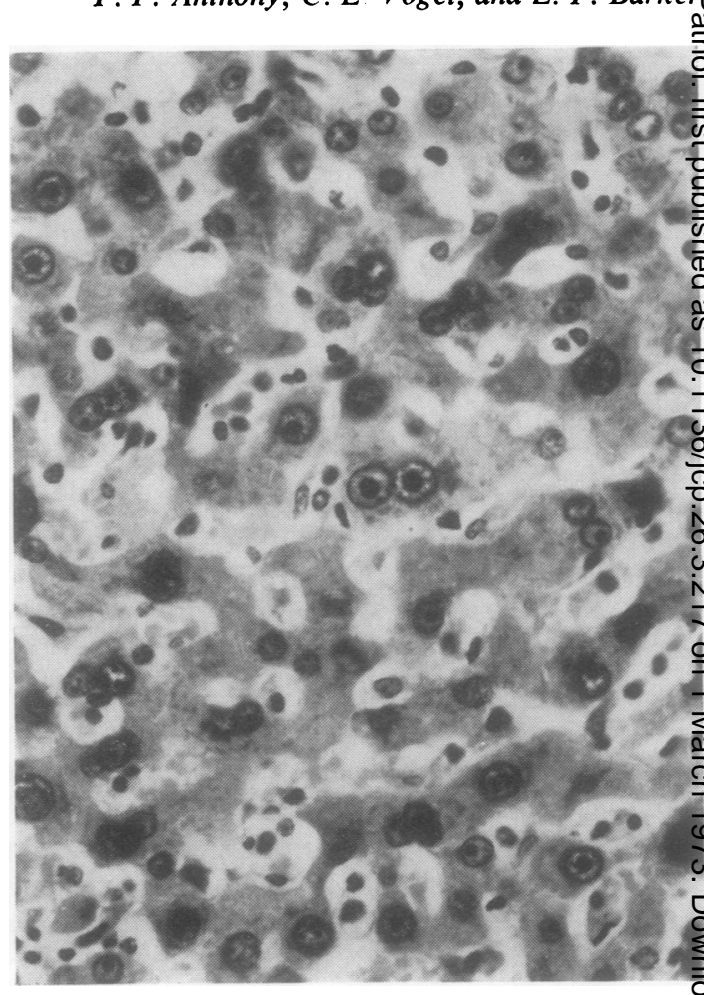

Fig. 2

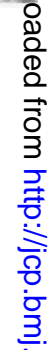

Fig 1 Slight nuclear variability, binucleation, and Kupffer cell hyperplasia in the liver of a Ugandan patienis suffering from malnutrition, Salmonella garoli diarrhoea, 3 and pneumococcal pneumonia. In addition, fatty change is also present (haematoxylin-eosin $\times 300$ ).

Fig 2 Liver cell dysplasia showing nuclear and cytoplasmic enlargement with gross nuclear pleomorphism ando multinucleation. Nucleoli are prominent. Note that this photomicrograph was taken at the same magnification as $\mathbb{N}$ fig 1 (haematoxylin-eosin $\times 300$ ).

Fig 3 A well defined group of dysplastic liver cells (top in a cirrhotic nodule (haematoxylin-eosin $\times 100$ ). 


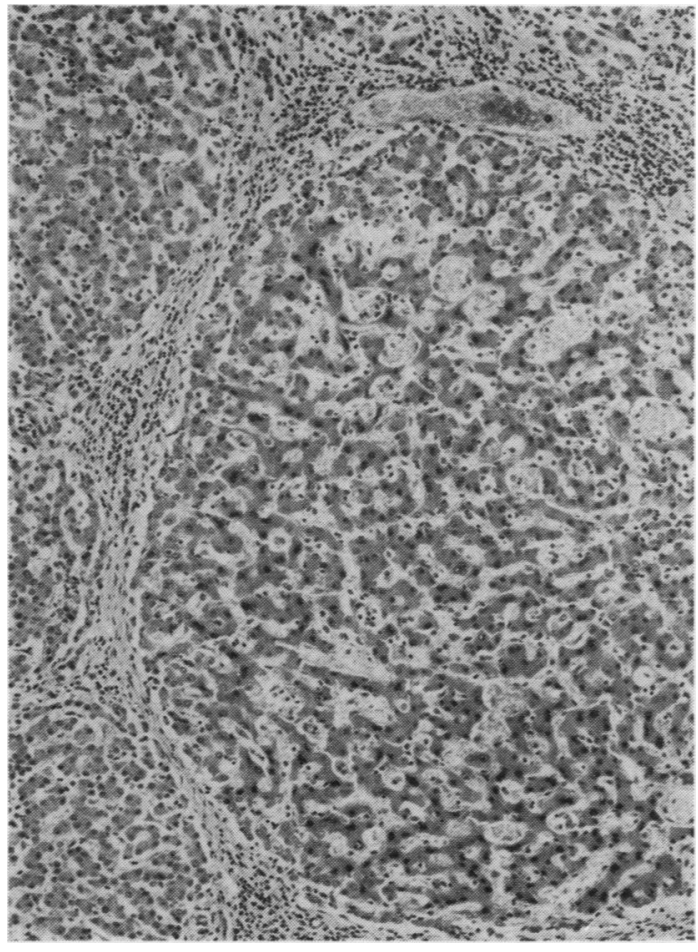

Fig 4 An entire cirrhotic nodule showing liver cell dysplasia (haematoxylin-eosin $\times 50$ ).

commented upon (Hutt, 1971). As illustrated in fig 1 these consist of slight nuclear variability, the presence of occasional double nuclei, and an increase in the number of Kupffer cells. In addition, portal tract inflammation and fibrosis are often present. It is reasonable to assume that these represent a response to the many toxic and infective agents of a tropical environment. Such changes are so common that they call for no special comment in the reporting of routine clinical liver biopsy material in Uganda.

These non-specific reactive changes must be clearly distinguished from liver cell dysplasia which is defined by the following criteria as illustrated in figures 2 to 5 .

Cellular enlargement, nuclear pleomorphism with hyperchromasia, and multinucleation are invariably present and are the main identifying features of the lesion. Enlargement is both nuclear and cytoplasmic and is generally two to threefold. The nuclearcytoplasmic ratio remains normal. Intranuclear inclusions may be seen and nucleoli are prominent.

Cytoplasmic staining is normal though occasionally more glycogen or less is present than in surrounding non-dysplastic liver. Intracytoplasmic bile

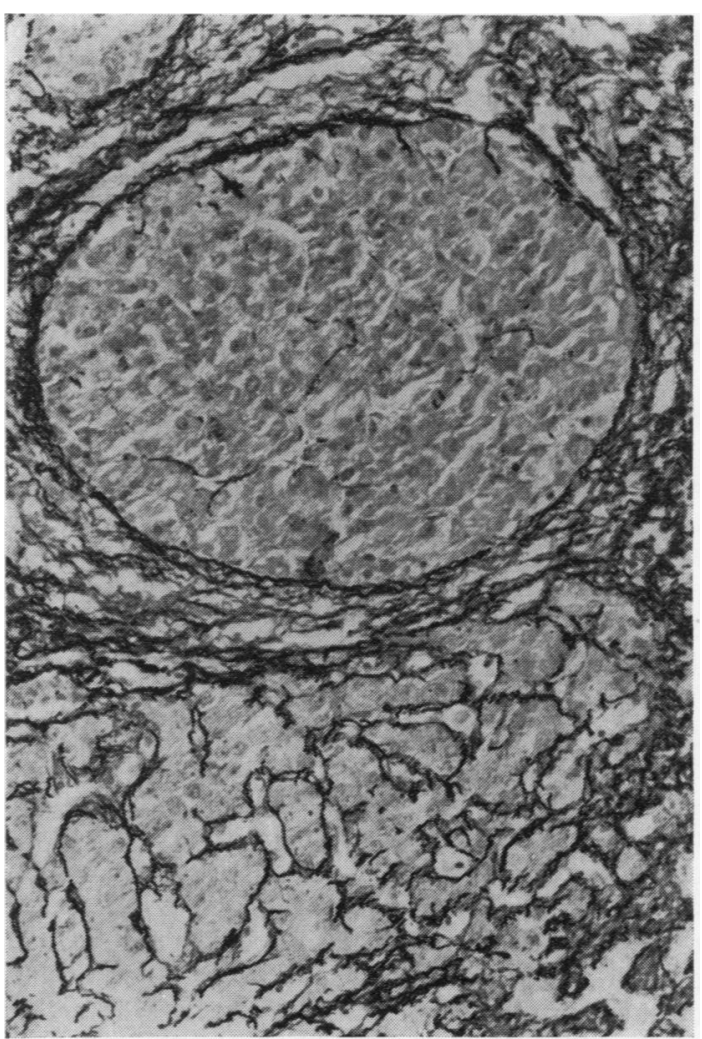

Fig 5 A nodule of liver cell carcinoma, devoid of reticulin, is shown in the top half of the field next to dysplastic liver cells below which have retained their normal reticulin framework (Gordon and Sweet's reticulin $\times 150$ ).

droplets are occasionally seen in the absence of any evidence of bile duct obstruction. The liver cell plates may be irregular but retain their reticulin framework and normal arangement of sinusoids.

These changes, when present, are multiple throughout the liver and occur in groups of liver cells or affect a whole cirrhotic nodule.

The appearances are sufficiently striking to be easily observed under low magnification.

\section{Material and Methods}

The presence or absence of liver cell dysplasia was assessed in histological material from 695 livers of Ugandan African patients admitted to the wards of New Mulago Hospital and the Solid Tumour Centre, Uganda Cancer Institute, Makerere University, Kampala. This comprised 207 necropsies carried out on all patients who died with cirrhosis 
and primary carcinoma of the liver in the years 1964 to 1968 (retrospective series) and 288 patients who were diagnosed to have these two diseases in all necropsies, laparotomies, and needle biopsies in the period May 1969 to April 1972 (prospective series). To this material were added necropsy sections of normal livers from 200 patients who had died from a wide variety of diseases, including tumours metastatic to the liver, taken at random during the period May 1969 to October 1971.

No selection was applied other than availability of sufficient histological material for assessment. In the retrospective and prospective series of patients with cirrhosis and primary carcinoma of the liver material was judged insufficient in 143 cases and these were rejected. The total of 552 cases left for study comprised 200 normal livers as above, 15 normal livers with primary bile duct (cholangiocellular) carcinoma, 43 normal livers with primary liver cell (hepatocellular) carcinoma, 170 cases of cirrhosis, and 124 cases of cirrhosis and liver cell carcinoma. The overall prevalence of liver cell dysplasia, its age and sex distribution, relationship to the presence and type of cirrhosis and primary liver carcinoma were determined in all cases. Standard paraffin sections were stained with haematoxylin and eosin supplemented by Gordon and Sweet's reticulin, the periodic acid-Schiff reaction before and after diastase, and Lendrum's martius-scarlet-blue method as necessary.

The presence of HAA was tested for in 125 cases by complement fixation (Shulman and Barker, 1969) and counterelectrophoresis (Gocke and Howe, 1970). Alpha-fetoprotein (AFP) was assayed in 134 cases by immunodiffusion (Abelev, 1968).

Data were statistically analysed using the chi square test.

\section{Results}

PREVALENCE

Table I shows that liver cell dysplasia may occasionally occur in patients suffering from a variety of diseases, including cancer of other organs with or

\begin{tabular}{lrll}
\hline & No. & \multicolumn{2}{l}{ Dysplasia $(\%)$} \\
\hline Normal livers $^{1}$ & 200 & 2 & $(1)$ \\
Normal livers with primary bile duct carcinoma & 15 & 0 & $(0)$ \\
Normal livers with primary liver cell carcinoma & 43 & 3 & $(6 \cdot 9)$ \\
Cirrhotic livers & 170 & $35(20 \cdot 3)$ \\
$\begin{array}{l}\text { Cirrhotic livers with primary liver cell } \\
\text { carcinoma }\end{array}$ & 124 & $80(64 \cdot 5)$ \\
\hline
\end{tabular}

Table I Liver cell dysplasia in 552 normal, cirrhotic, and cancerous livers

${ }^{1}$ Indicates absence of cirrhosis or primary liver carcinoma but includes metastatic tumours. without liver metastases. One of the two patients with dysplasia in this group of 200 died of miliary tubercu $\vec{\Rightarrow}$ losis, the other had an amoebic abscess of the liver? which had been clinically misdiagnosed as carcinomac of the liver and treated with large doses of metho- $\frac{\bar{c}}{\bar{m}}$ trexate. Liver cell dysplasia was not seen in associa $\frac{\Phi}{8}$ tion with 15 bile duct carcinomas all of which $\stackrel{\mathbb{}}{\Omega}$ developed in normal, ie, non-cirrhotic, livers.ఋ Dysplasia was present, however, in three of $43 \vec{\circ}$ $(6.9 \%)$ liver cell carcinomas arising in non-cirrhoticlivers. In all only five of 120 cases of liver cellw dysplasia were seen in these three groups comprising? 258 patients and these are excluded from furthero analysis. Nearly all cases of dysplasia (115 of 120) were seen in the 294 cirrhotic patients. The differencei $\dot{ }$ in the prevalence of dysplasia between normal and $\mathrm{N}$ cirrhotic livers is obvious $\left(\chi^{2}=111.64\right.$; P less than ${ }^{\gamma}$ $0.0001)$. Amongst cirrhotic patients dysplasia was? present in 35 of $170(20.3 \%)$ of those with cirrhosis alone and in 80 of $124(64.5 \%)$ of those with cirrhosiso and liver cell carcinoma, a difference that was alsoo statistically highly significant $\left(\chi^{2}=58 \cdot 10\right.$; P less than $0 \cdot 001$ ).

AGE

The mean age of 294 cirrhotic patients with or without liver cell dysplasia is shown in table II which iso grouped into those with cirrhosis only and those withő cirrhosis and liver cell carcinoma. Though there was å fairly wide scatter around the mean in all groups it $\overrightarrow{0}$ does appear that those with cirrhosis who showed no3 dysplasia were, on average, 10 years younger than those who did. They, in turn, were some six years: younger than those with cirrhosis and liver celfo. carcinoma. In this latter group there was no longe? a detectable age difference between those with and those without dysplasia.

\begin{tabular}{|c|c|c|}
\hline & No. & $\begin{array}{l}\text { Mean Age }(y r) \\
( \pm S D)\end{array}$ \\
\hline \multicolumn{3}{|l|}{ Cirrhosis only } \\
\hline Without dysplasia & 125 & $25 \cdot 4(=14 \cdot 6)$ \\
\hline With dysplasia & 34 & $35 \cdot 5( \pm 15 \cdot 1)$ \\
\hline \multicolumn{3}{|c|}{ Cirrhosis and liver cell carcinoma } \\
\hline Without dysplasia & 43 & $41 \cdot 2( \pm 14 \cdot 6)$ \\
\hline With dysplasia & 78 & $41 \cdot 2(\div 13 \cdot 1)$ \\
\hline
\end{tabular}

Table II Mean ages of 280 patients with cirrhosis (with or without associated liver cell carcinoma) and liver cell 은 dysplasia 1

${ }^{1}$ The ages of 14 patients were not known.

SEX

The male to female ratio for the whole group of $294 \stackrel{\mathbb{9}}{\square}$ cirrhotic patients was 3.7 to 1 , the male preponder $\triangle$ ance being more marked for those with cirrhosis and liver cell carcinoma $(5 \cdot 2$ to 1$)$ than those witho 
cirrhosis alone ( 3 to 1$)$. It may be seen from the figures shown in table III that 98 of $232(42.2 \%)$ males showed dysplasia compared with 17 of 62 $(27.4 \%)$ females $\left(\chi^{2}=4.51\right.$; P less than 0.05). Most of this difference was observed amongst those with cirrhosis alone: 31 of $128(24.2 \%)$ males had dysplasia compared with four of $42(9.5 \%)$ females. Dysplasia was present in an equal proportion of both sexes amongst those with cirrhosis and liver cell carcinoma: in 67 of $104(64.4 \%)$ males and 13 of 20 $(65 \%)$ females.

\begin{tabular}{|c|c|c|c|}
\hline & No. & Males & Females \\
\hline $\begin{array}{l}\text { Cirrhosis only } \\
\text { Without dysplasia } \\
\text { With dysplasia }\end{array}$ & $\begin{array}{r}170 \\
135 \\
35\end{array}$ & $\begin{array}{rr}128 & \\
& 97 \\
& 31\end{array}$ & $\begin{array}{r}42 \\
38 \\
4\end{array}$ \\
\hline $\begin{array}{l}\text { Cirrhosis and liver cell carcinoma } \\
\text { Without dysplasia } \\
\text { With dysplasia }\end{array}$ & $\begin{array}{r}124 \\
44 \\
80\end{array}$ & $\begin{array}{rr}104 & 37 \\
& 67\end{array}$ & $\begin{array}{rr}20 & 7 \\
13\end{array}$ \\
\hline
\end{tabular}

Table III Sex distribution of liver cell dysplasia in 294 cirrhotic patients with and without liver cell carcinoma

TYPE OF CIRRHOSIS

The criteria used for distinguishing the various types of cirrhosis were those in general use as reviewed by Scheuer (1968). Table IV shows that only one of 29 patients with nutritional (fatty, micronodular) cirrhosis had dysplasia compared with 114 of 265 patients with other types of cirrhosis $\left(\chi^{2}=17 \cdot 21\right.$; $P$ less than 0.001 ). The highest proportions were found in the macronodular (posthepatitic and postnecrotic) types. In all types of cirrhosis dysplasia was seen more frequently in the presence of liver cell carcinoma, the actual proportion being similar to the overall figures presented in table I, an approximately three-fold increase. There were only eight of 124 cases of liver cell carcinoma associated with micronodular cirrhosis.

\begin{tabular}{lrr}
\hline Type of Cirrhosis & No. & Dysplasia \\
\hline Nutritional & 29 & $1(3.4 \%)$ \\
Posthepatitic & 140 & $65(46.4 \%)$ \\
Postnecrotic & 44 & $23(52 \cdot 2 \%)$ \\
Mixed & 81 & $26(32.0 \%)$ \\
\hline
\end{tabular}

Table IV Liver cell dysplasia and type of cirrhosis

(Gall's classification) in 294 patients

\section{HEPATITIS-ASSOCIATED ANTIGEN}

Hepatitis-associated antigen was tested for in 104 cirrhotics with or without liver cell carcinoma and was found to be present in $41(39.4 \%)$. Table V presents the details of the relationship between HAA, dysplasia, and cirrhosis with or without associated liver cell carcinoma. It may be seen that there was a difference in the prevalence of HAA between those with dysplasia ( 31 of 43 or $72 \%$ ) and those without (10 of 61 or $16.3 \%$ ) that was statistically highly significant $\left(\chi^{2}=32.77 ; \mathrm{P}\right.$ less than 0.0001). The strength of the association between HAA and dysplasia was the same in cirrhotics with and without liver cell carcinoma.

\begin{tabular}{|c|c|c|}
\hline & No. & $H A A$ \\
\hline $\begin{array}{l}\text { Dysplasia present } \\
\text { Cirrhosis only } \\
\text { Cirrhosis and liver cell carcinoma }\end{array}$ & $\begin{array}{rr}43 & 14 \\
& 29\end{array}$ & $\begin{array}{l}31(72 \cdot 0 \%) \\
9(64.2 \%) \\
22(75.8 \%)\end{array}$ \\
\hline $\begin{array}{l}\text { Dysplasia absent } \\
\text { Cirrhosis only } \\
\text { Cirrhosis and liver cell carcinoma }\end{array}$ & $\begin{array}{ll}61 & \\
& 46 \\
& 15\end{array}$ & $\begin{array}{r}10(16.3 \%) \\
7(15.2 \%) \\
3(20.0 \%)\end{array}$ \\
\hline
\end{tabular}

Table V Association between HAA and liver cell dysplasia in 104 cirrhotic patients with or without liver cell carcinoma

\section{ALPHA-FETOPROTEIN}

Alpha-fetoprotein was tested for in 60 cirrhotics of whom 14 had dysplasia and all were negative. It was also tested for in 45 cirrhotics with liver cell carcinoma of whom $32(71 \cdot 1 \%)$ were positive. There was no difference between those with and without dysplasia.

\section{Discussion}

The results of this study suggest that liver cell dysplasia, as defined above, is a premalignant change. This rests on the following arguments.

Liver cell dysplasia is seen only occasionally in people suffering from a variety of diseases, including bile duct carcinoma and malignant tumours metastatic to the liver. It is present in a small proportion of normal livers bearing liver cell carcinoma. It is seen in approximately one-fifth of patients with cirrhosis and two-thirds of cirrhotics with liver cell carcinoma. This increase in prevalence from normal to cirrhosis and carcinoma is a statistically significant one.

Cirrhotic patients without dysplasia are, on average, 10 years younger than those with dysplasia and cirrhotics with dysplasia are, again on average, some six years younger than those with cirrhosis and carcinoma. This suggests that with time there is a progression of cirrhosis to dysplasia and, ultimately, to liver cell carcinoma. These age differences may be regarded as analogous to dysplasia, carcinoma in situ, and invasive carcinoma of the uterine cervix and other sites.

Dysplasia occurs significantly more frequently in males than in females, the differences being greatest amongst those with cirrhosis alone. In Uganda as elsewhere in Africa, there is a marked preponderance of males over females in liver cell carcinoma (Doll, Payne, and Waterhouse, 1966) and males with 
cirrhosis may have a higher chance of developing carcinoma than females (Shaper, 1970). Both of these findings are further supported in this study.

Dysplasia is found almost exclusively in macronodular (posthepatitic and postnecrotic) types of cirrhosis and very rarely in the micronodular (nutritional, fatty) type. It is a well established fact that liver cell carcinoma arises most frequently in the grossly scarred, macronodular types of cirrhosis (Gall, 1960; Lee, 1966). This was also found to be so in this study.

Available evidence suggests that there may be a geographical variability in the occurrence of liver cell dysplasia in that it appears to be less common in North America (Steiner and Davies, 1957) and in Europe (Scheuer, 1968). This lower incidence would parallel the lower incidence of liver cell carcinoma in these areas (Doll et al, 1966).

Liver cell dysplasia itself is not a malignant change, though its gross nuclear abnormalities, multifocal origin, and nodular pattern may cause difficulty in distinguishing it from nodules of liver cell carcinoma (Higginson and Steiner, 1961). The main distinguishing features of dysplasia from carcinoma are the following:

Dysplastic liver cells show cytoplasmic as well as nuclear enlargement and, unlike liver cell carcinoma, the nuclear/cytoplasmic ratio remains within normal limits.

Cytoplasmic staining and granularity are usually normal in dysplasia whereas in liver cell carcinoma there is often some cytoplasmic basophilia.

In dysplastic nodules the reticulin pattern is usually normal or slightly increased whereas in carcinomatous nodules the reticulin is deficient or lost altogether.

Most importantly, this study has shown that the AFP test is negative in cirrhosis with dysplasia. If dysplasia itself was a malignant change a proportion of cases should be positive. Over $70 \%$ of liver cell carcinomas were AFP positive in this series.

The data presented in this study clarify the uncertainty expressed previously about the relationship between dysplasia and carcinoma. Steiner and Davies (1957) argued that as the morphological appearances of 'liver cell atypia' were different from liver cell carcinoma arising in the same liver, there was no relationship between them. There is, in fact, no reason why there should be a morphological similarity. Scheuer (1968) noted that atypical cellular changes could persist for years without carcinoma developing. This is compatible with the natural history of the lesion as described above and of dysplasia and carcinoma in situ at other sites.

The precise nature of liver cell dysplasia remains uncertain. It is premalignant only in the sense that its presence is associated with an increased risk of liver cell carcinoma. It is of interest that it shows $a \overrightarrow{7}$ strong association with the presence of HAA. We have shown previously that in Uganda there exists anc approximately 10 -fold increase in the prevalence of HAA in cirrhosis (Maynard, Sadikali, Anthony, and Barker, 1970) and liver cell carcinoma (Vogel $\varrho$ Anthony, Sadikali, and Barker, 1970) as comparedes with the general hospital population. We have also $\overrightarrow{0}$ noted that liver cell dysplasia had a statisticallysignificant association with the presence of HAA inc. both groups of patients (Anthony et al 1972). The data in this study are an extension of the earlier? observations in a larger number of patients and areos fully supportive. They suggest that dysplasia maycu indeed be causally related to HAA and chronic infection with the long-incubation (serum or B) hepatitis virus. The relative rarity of dysplastic changes in cirrhosis in the temperate zones (Steiner $\vec{z}$ and Davies, 1957; Higginson and Steiner, $1961 ;$ Scheuer, 1968) would, on the other hand, parallel the $?$ low prevalence of HAA in these areas (Prince, 1971). $\frac{\vec{c}}{0}$

Failure to find the typical virus-core-like particles in the nuclei of liver cells from 17 cases of liver cell ${ }^{\omega}$ carcinoma in this material (O'Conor, Tralka, Henson, and Vogel, 1972) is in contrast with the frequent finding of these particles in the hepatocyteso of chronically infected, immunosuppressed patientso (Huang, 1971) and asymptomatic HAA carriers $\cong$ (Caramia, De Bac, and Ricci, 1972). This suggests $a_{\hat{O}}^{\vec{F}}$ discordance between HAA production and virus 3 synthesis in some patients with chronic virus $\mathrm{B}$ infection.

The work of Harris and his coworkers on cello fusion and malignancy may be relevant in this:context (Harris, Miller, Klein, Worst, and Tachi- 3 bana, 1969). They showed that the malignanto potential of cells from three types of tumours, one $\frac{3}{3}$ of which has been induced by polyoma virus, could be ${ }_{\circ}$ suppressed when fused with certain non-malignant cells. The hybrids resulting from such fusions produced segregants in which a loss of chromosomes was associated with reversion to malignant behav- $\sim$ iour after a variable period of time. It may be N speculated that HAA induces malignant change in N liver cells which then fuse with normal liver cells in ${ }_{\sigma}^{\omega}$ their vicinity to form large, abnormal, dysplastic cells. Malignancy is thereby suppressed. In some,

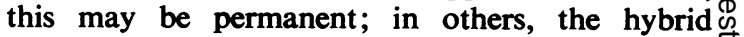
gradually escapes through loss of chromosomal material and malignant behaviour is then resumed. Much of the circumstantial evidence in this study $\overrightarrow{\mathbb{D}}$ supports this hypothesis. Ultimately, it is hoped that $\stackrel{\bigcirc}{\odot}$ liver culture systems will be developed to test the $\varrho$ effect of HAA-positive human material. Numerous examples of chromosomal abnormalities in cells 8 
infected with a wide variety of oncogenic and nononcogenic viruses have already been described (Aula, Nichols, and Levan, 1968).

For practical purposes it may be suggested that the presence of liver cell dysplasia in a patient, particularly in the presence of cirrhosis, must be regarded as evidence of an increased risk of liver cell carcinoma. Such patients should be followed up by serial testing for alpha-fetoprotein. It is hoped that early detection of malignancy in this high risk group may lead to better results of surgical treatment for a tumour of which the prognosis is at present almost hopeless.

We wish to acknowledge the help given by Professors M. S. R. Hutt, R. A. B. Drury, and Dr R. Owor of the Department of Pathology, Makerere University, Kampala, where part of this work was carried out during the tenure of a senior lectureship by one of us (P.P.A.) in 1969/70 and thank them for providing histological material for study thereafter.

\section{References}

Abelev, G. I. (1968). Production of embryonal serum alpha-globulin by hepatomas: review of experimental and clinical data. Cancer Res., 28, 1344-50.

Anthony, P. P. (1972). Primary carcinoma of the liver. A study of 282 cases in Ugandan Africans. J. Path., in the press.

Anthony, P. P., Vogel, C. L., Sadikali, F., Barker, L. F., and Peterson, M. R. (1972) Hepatitis-associated antigen and antibody in Uganda : correlation of serological testing with histopathology. Brit. med. J., 1, 403-406.

Aula, P., Nichols, W. W., and Levan, A. (1968) Virus-induced chromosome changes. Ann. N.Y. Acad. Sci., 155, 737.

Butler, W. H. (1971). Pathology of liver cancer in experimental animals. In Liver Cancer, IARC Scientific Publications No. 1, Lyon.

Caramia, F., De Bac, C., and Ricci, G. (1972). Virus-like particles within hepatocytes of Australia antigen carriers. Amer. J. Dis. Child., 123, 309-311.

Doll, R., Payne, P., and Waterhouse, J. (1966). Cancer Incidence in Five Continents, Vol. 1. Springer for I.U.C.C. Berlin.

Edmondson, H. A., and Steiner, P. E. (1954). Primary carcinoma of the liver: a study of 100 cases among 48,900 necropsies. Cancer (Philad.), 7, 462-503.

Gall, E. A. (1960). Primary and metastatic carcinoma of the liver. Relationship to hepatic cirrhosis. Arch. Path., 70, 226-232.

Gocke, D. J., and Howe, C. (1970). Rapid detection of Australia antigen by counterimmunoelectrophoresis. J. Immunol., 104, 1031-32.

Harris, H., Miller, O. J., Klein, G., Worst, P., and Tachibana, T. (1969). Suppression of malignancy by cell fusion. Nature (Lond.), 223, 363-368.

Higginson, J., and Steiner, P. E. (1961). Definition and classification of malignant epithelial neoplasms of the liver. Acta Un. int. Cancr., 17, 593-603.

Huang, S. (1971). Hepatitis-associated antigen hepatitis. Amer. J. Path., 64, 483-492.

Hutt, M. S. R. (1971) Some aspects of liver disease in Ugandan Africans. Trans, roy. Soc. trop. Med. Hyg., 65, 273-285.

Lee, F. I. (1966) Cirrhosis and hepatoma in alcoholics. Gut, 7, 77-85.

Maynard, E. P., III, Sadikali, F., Anthony, P. P., and Barker, L. F. (1970). Hepatitis-associated antigen and cirrhosis in Uganda. Lancet, 2, 1326-1328.

O'Conor, G. T., Tralka, T. S., Henson, E., and Vogel, C. L. (1972). Ultrastructural survey of primary liver cell carcinomas from Uganda. J. nat. Cancer Inst., 48, 587-603.

Prince A. M. (1971). Role of serum hepatitis virus in chronic liver disease. Gastroenterology, 60, 913-921.

Scheuer, P. J. (1968). Liver Biopsy Interpretation. Bailliere, Tindall, and Cassell, London.

Shaper, A. G. (1970). Cirrhosis and primary liver cell carcinoma in Uganda. Trop. geogr. Med., 22, 161-166.

Shulman, N. R., and Barker, L. F. (1969). Virus-like antigen, antibody and antigen-antibody complexes in hepatitis measured by complement fixation. Science, 165, 304-306.

Steiner, P. E., and Davies, J. N. P. (1957). Cirrhosis and primary liver carcinoma in Uganda Africans. Brit. J. Cancer, 11, 523-534.

Vogel, C. L. Anthony, P. P., Mody, N., and Barker, L. F. (1970). Hepatitis-associated antigen in Ugandan patients with hepatocellular carcinoma. Lancet, 2, 621-624. 